\title{
The role of regional migration policy in the development of migration processes
}

\section{Roman Stakanov}

Institute of International Relations, Taras Shevchenko National University of Kyiv,

36/1 Melnikova str., 04119, Kyiv, Ukraine

PhD, Associate Professor, Department of World Economy and International Economic Relations

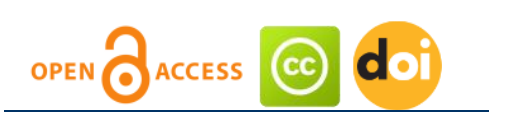

Article history:

Received: February 19, 2018

1st Revision: March 7, 2018

Accepted: March 25, 2018

JEL classification:
F22
O15
R23

DOI:

10.14254/jems.2018.3-1.7

\begin{abstract}
The paper discusses an empirical examination of the impact of regional integration on the processes of international labour migration. For this purpose, the data from 16 regional integration organisations, accounting for more than $90 \%$ of the world's immigration, were used. Despite different levels of integration, all regional organisations entered into separate agreements liberalising the movement of certain categories of workers. Our research has shown that the key factor determining the increase in the number of migrants is the economic growth in a host migrant region. On the other hand, the growth of the level of integration positively influences an inflow of immigrants, although this connection is not strong.
\end{abstract}

Keywords: regional migration policy, international labour migration, regional integration associations, regional integration, regional trade agreements, correlation-regression relationship.

\section{Introduction}

The process of labour migration liberalisation is actively progressing within the frameworks of regional integration associations; at the same time, regional programs of free admission of citizens from the countries that are parties to such regional groups throughout the world are being developed. The cooperation between international organisations and regional associations helps to keep the rights and social protection of migrants in the focus. Regional consultation processes are paying considerable attention to the management of migratory flows. However, the insufficient mandate of such regional-level consultation processes prevents them from making legally binding decisions on the implementation of migration policy, while the pivotal role in regulating labour migration remains in the domain of the national and bilateral levels of governance.

Given that the problem of international trade regulation is most closely related to the issue of regional economic integration, migration questions raised in the context of trade integration have a significant window of opportunity for further intensification at both the global and regional levels. In view of the limited availability of a comprehensive toolkit for regulating labour migration at the global level, the ability to manage migration processes within the framework of regional integration

Corresponding author: Roman Stakanov

E-mail: roman.stakanov@gmail.com

This open access article is distributed under a Creative Commons Attribution (CC-BY) 4.0 license. 
associations takes on essential significance. Certain aspects of such regulation emerge in varying degrees even at the level of regional trade agreements (RTA).

The signing of an RTA reduces the bilateral component of migration costs, increasing the number of migrants in the long run. This effect intensifies substantially if provisions on the simplification of visa procedures were adopted within the framework of an RTA, which in turn reduces the bureaucratic costs of migration. Regulations on the liberalisation of movement of persons within the framework of an RTA may have a number of approaches. In most cases, they provide for easier admission to a country, and, less often, access to the labour market and the right of residence. Issues related to the movement of persons are not always envisaged in an RTA explicitly, but may be included in the related treaties. Similarly, agreements relating to the liberalisation of the movement of persons may have different stages of implementation in different countries. The agreements in question may include different types of migration: cover all mobility of individuals, ensure freedom of migration for its individual types, in particular for highly skilled workers, facilitate the movement of service providers, simplify procedures for the movement of investors, and facilitate other types of migration.

\section{Materials and Methods}

Based on the data on the level of regional economic integration, the existence of agreements on free movement of persons within regions and sub-regions, and also the actual degree of implementation of such agreements, we have compiled the Matrix of regional associations (Table 1), which will serve as the starting point for further modelling of the impact of a regional migration policy on the migration dynamics and the condition of the labour market in the studied parts of the world. The classical integration levels of $\mathrm{B}$. Ballasa were taken as a basis of integration levels according to the matrix with some amendments necessary for this study (Level 0 - Free Trade Area establishment negotiations, Level 1 - a Free Trade Area in force, Level 2 - a Customs Union, Level 3 - a Common Market, Level 4 - an Economic Union, Level 5 - Full Integration (for the purposes of our Matrix, Level 5 takes into account the existence of the elements of a common migration policy towards third countries). Due to the special attention to the regulation of migration flows, a number of regional integration associations that declared the transition to the stages of common market and economic union, continue to retain restrictions on the various levels for labour migration, which is reflected in the Matrix (specific associations having 3-4 integration levels, have the '-' mark in the column 'Free movement of workers').

Table 1: Matrix of regional integration associations*

No. $\quad$ Regional association Integration level*

\section{Special agreements on} the free movement of certain categories of workers / short-term visa-free travel

\begin{tabular}{cllcc}
\hline 1 & EU & 5 & visa-free travel & + \\
2 & ECCAS & 4 & + & - \\
3 & EAEU & 4 & + & + \\
4 & CARICOM & 4 & + & + \\
5 & GCC & 3 & + & - \\
6 & ASEAN & 3 & + & + \\
7 & MERCOSUR & 3 & + & + \\
8 & CAN & 2 & + & - \\
9 & ECOWAS & 2 & + & + \\
10 & SADC & 2 & + & - \\
11 & ANZCERTA & 1 & + & - \\
12 & COMESA & 1 & + & - \\
13 & NAFTA & 1 & + & - \\
14 & CIS & 1 & + & + \\
15 & SAARC & 1 & + & + \\
16 & IGAD & 0 & + & + \\
\hline
\end{tabular}

* - integration levels of specific integration associations can combine elements of different levels or exclude theoretically substantiated positions. Positioning according to the levels of integration is based on the prevailing characteristics within the framework of RTAs.

Source: Compiled by the author based on European Central Bank, 2004; OECD, 2016; United Nations, 2016. 
Table 1 shows that all key regional associations, regardless of the level of integration, entered into special agreements on free movement of certain categories of workers or on the liberalisation of short-term visa-free travel within the association. Moreover, despite the discrepancy between the classic stages of integration and a level of liberalisation of regional migration, as demonstrated in the previous sections of the dissertation, full freedom of movement of workers is more frequently found at a higher level of integration (in 5 out of 7 in the RTAs of Levels 3-5) than in an RTA of a lower level of integration (2 out of 9 in the RTAs of Levels $0-2$ ).

At the same time, the level of integration is not the only factor that determines the peculiarities of migration flows within RTAs. The main driver of potential immigration that influences the labour market and the economy of a receiving country is the effectiveness of migration policy. The economic impact of labour migration varies widely in countries that use supply and demand-driven migration systems. The systems based on migration scores systems increase both the absolute number of highly skilled migrants and a relative share of workers with higher qualification in the overall migration structure. Demand-driven migration systems, however, do not generally change the structure of immigration towards an increase in the share of human capital.

Bilateral agreements that serve for the recognition of qualifications obtained abroad, as well as the transfer of social security between countries contribute to the growth of flows of highly skilled workers in addition to an increase in the selectivity of immigrant flows. When a country belongs to a regional agreement stipulating a free movement of workers, such factor increases the total number of highly skilled immigrants, but on the other hand, this membership in a regional association contributes to reducing the overall selective capacity of the country's migration policy in turn (Czaika \& Parsons, 2016).

In order to carry out an empirical verification of the theoretically found statement about a positive impact of regional integration on international labour migration, we will use the data shown in the Regional integration associations matrix (Table 1); the UN data will be used to calculate the labour migration indicators for the period of 2010-2015 (United Nations, 2016). The data on increases in immigration were obtained from 175 countries, which in 2015 accounted for 213.4 million migrants (87.55\% of their total number). Only such regional centres of immigration as China, Hong Kong, Switzerland, Japan, Israel, Norway and South Korea, together accounting for about $5 \%$ of global immigration, were not covered by this study. At the same time, the exclusion from the study of the Middle East countries (Iran, Iraq, Syria, Jordan, Turkey, Lebanon, Yemen, the Palestinian Territories), which together also account for $5 \%$ of immigration, is justified because migration to this region was caused mainly by humanitarian reasons, and as such does not belong to the subject of our research. Thus, given that more than $90 \%$ of global emigration was covered by this study, its results can be considered significant for all international labour migration in the world economy.

The empirical proof of the hypothesis about the existence of a linear regression relationship between the level of economic integration of countries and the number of migrants requires the construction of a mathematical model of an object containing two groups of elements:

1) a characteristic of the object to be determined (unknown values), - vector $Y=\left(y_{j}\right)$;

2) the characteristics of the external changing conditions (in relation to the modelled object), - vector $X=\left(x_{j}\right)$;

The sets of $X$ parameters can be regarded as exogenous values (i.e., the ones determined outside the model frame), while the values belonging to vector $\mathrm{Y}$ - as endogenous values (i.e., those determined with the help of the model).

A mathematical model, therefore, should be seen as a conditional mechanism for transforming the external conditions of the object X into the characteristics of the object $\mathrm{Y}$ that have to be found. This type of interconnection of variables is considered a functional one, and it lies in the construction of a functional model whose task is understanding the essence of an object through the most important manifestations of its essence: activity, functioning, behaviour. At the same time, the internal structure of the object is not examined; therefore, the information about the structure is not used. Functional econometric models describe in a quantitative manner the relationship between the initial values $X$ of an economic system and the resulting value $Y$. In general, an econometric model can be written as follows:

$$
Y=f(x)+u
$$

where $X$ is the initial economic values; $u$ is a random (or stochastic) element.

Given the fact that the dependent variable $Y$ is dependent upon $u$, it is also a stochastic value, and therefore when a correlation-regression relationship is determined between the economic 
values, there arises a need for a decrease in certain permissible limits of the error caused by the existence of a random element, which in practice is achieved through a linear approximation of the model parameters:

$$
Y=a_{0}+a_{1} X+u
$$

where $\mathrm{a}_{0}$ and $\mathrm{a}_{1}$ are unknown parameters.

Dispersion of the independent variables on the coordinate plane is the main factor of data distortion in a regression model. The least squares method (LSM), the principle of minimising the sum of the squared deviations of points from a certain line, which generally describes a regression dependence, is being used in order to increase the adequacy of linear regression. This method seeks to find such $\mathrm{a}_{0}$ and $\mathrm{a}_{1}$, for which $\sum_{i=1}^{n} u_{i}^{2}$ has the least value.

The necessary condition for minimising a random variable is that the partial derivatives of the function $\mathrm{f}(\mathrm{x})$ for each of the parameters $\mathrm{a}_{0}$ and $\mathrm{a}_{1}$ equal to zero. LSM for a linear dependence will be written as:

$$
F=\sum_{i=1}^{n} u_{i}^{2}=\sum_{i=1}^{n}\left(y_{i}-\hat{y}_{i}\right)^{2}=\sum_{i=1}^{n}\left(y_{i}-\hat{a}_{0}-\hat{a}_{1} x_{i}\right)^{2} \rightarrow \min
$$

provided that

$$
\left\{\begin{array}{l}
\frac{\partial F}{\partial a_{0}}=-2 \sum_{i=1}^{n}\left(y_{i}-\hat{a}_{0}-\hat{a}_{1} x_{i}\right)=0 \\
\frac{\partial F}{\partial a_{1}}=-2 \sum_{i=1}^{n} x_{i}\left(y_{i}-\hat{a}_{0}-\hat{a}_{1} x_{i}\right)=0
\end{array}\right.
$$

By performing elementary transformations, we are obtaining a system of linear equations:

$$
\left\{\begin{array}{c}
\sum_{i=1}^{n} y_{i}-n \hat{a}_{0}-\hat{a}_{1} \sum_{i=1}^{n} x_{i}=0 \\
\sum_{i=1}^{n} x_{i} y_{i}-\hat{a}_{0} \sum_{i=1}^{n} x_{i}-\hat{a}_{1} \sum_{i=1}^{n} x_{i}^{2}=0
\end{array}\right.
$$

which leads us to:

$$
\left\{\begin{array}{c}
n \hat{a}_{\mathrm{O}}+\hat{a}_{1} \sum_{i=1}^{n} x_{i}=\sum_{i=1}^{n} y_{i} \\
a_{\mathrm{O}} \sum_{i=1}^{n} x_{i}+a_{1} \sum_{i=1}^{n} x_{i}^{2}=\sum_{i=1}^{n} x_{i} y_{i}
\end{array}\right.
$$

By solving the system of linear equations, we obtain the estimates of the parameters $a_{0}$ and $a_{1}-\widehat{a_{0}}$ and $\widehat{a_{1}}$ :

$$
\begin{gathered}
\hat{a}_{1}=\frac{\sum_{i=1}^{n} x_{i} \sum_{i=1}^{n} y_{i}-n \sum_{i=1}^{n} x_{i} y_{i}}{\left(\sum_{i=1}^{n} x_{i}\right)^{2}-n \sum_{i=1}^{n} x_{i}^{2}} \text { and } \\
\hat{a}_{0}=\frac{\sum_{i=1}^{n} x_{i} \sum_{i=1}^{n} x_{i} y_{i}-\sum_{i=1}^{n} x_{i}^{2} \sum_{i=1}^{n} y_{i}}{\left(\sum_{i=1}^{n} x_{i}\right)^{2}-n \sum x_{i}^{2}} .
\end{gathered}
$$


An important stage in the construction of any regression model is the determination the significance (adequacy) of the obtained parameter estimates. There are various algorithms for conducting such a study, most of which involve an assessment of dependence of:

- the whole array of explanatory variables ( $\chi^{2}-$ "xi"- squared);

- each explanatory variable with the remaining variables ( $F$-criterion);

- each pair of explanatory variables ( $t$-criterion).

These criteria, when compared with their critical values, give reason to make explicit conclusions on the presence or absence of multicollinearity of explanatory variables and their adequacy to real processes that are modelled.

Let the vectors of the independent variables of an econometric model be $X_{1}, X_{2}, X_{3} \ldots X_{m}$. The elements of normalised vectors are calculated by the formula:

$$
x_{i k}^{*}=\frac{x_{i k}-\bar{x}_{k}}{\sqrt{\sigma_{x_{k}}^{2} n}},
$$

where $n$ is the number of observations $(i=\overline{1, n}) ; m$ is the number of explanatory variables $(k=\overline{1, m}) ; \bar{x}_{k}$ is the arithmetic mean of $k$-th of explanatory variables; $\sigma_{x_{k}}^{2}$ is the dispersion of $k$-th of an explanatory variable.

In order to detect multicollinearity, the correlation matrices of normalised variables need also to be found:

$$
r_{x x}=X^{*^{\prime}} X^{*}
$$

where $X^{*}$ is the matrix of normalised independent variables, $X^{*^{\prime}}$ is the matrix transposed to a matrix $X^{*}$.

The next step is to calculate the values of $\chi^{2}$ :

$$
\chi^{2}=-\left[n-1-\frac{1}{6}(2 m+5)\right] \ln \left|r_{x x}\right|
$$

where $\left|r_{x x}\right|$ is the determinant of the correlation matrix $r_{x x}$.

The value of this criterion is compared with the table value subject to $\frac{1}{2} m(m-1)$ degrees of freedom and the significance level $\alpha$. If $\chi_{\mathrm{act}}^{2}>\chi_{\mathrm{tabl}}^{2}$, then, there is multicollinearity in an array of independent variables.

The determination of the inverse matrix is performed by the formula:

$$
C=r_{x x}^{-1}=\left(X^{*} X^{*}\right)^{-1}
$$

And the calculation of F-criteria, respectively

$$
F_{k}=\left(c_{k k}-1\right) \frac{n-m}{m-1},
$$

where $c_{k k}$ are the diagonal elements of the matrix $C$. The actual values of the criteria are compared with the table values for $m-1$ and $n-m$ degrees of freedom and the significance level $\alpha$. If $F_{k}$ act $>F_{\text {tabl, }}$ then the relevant $k$-th explanatory variable adequately describes the process under examination.

The determination coefficient for each variable: 


$$
R_{k}^{2}=1-\frac{1}{c_{k k}}
$$

If the determination coefficient is close the figure of one, then the regression coefficients in general adequately explain the process under examination.

The next step is to calculate the t-criteria:

$$
t_{k j}=\frac{r_{k j} \sqrt{n-m}}{\sqrt{1-r_{k j}^{2}}}
$$

The actual values of the criteria $t_{k j}$ are compared with the table values subject to $n-m$ degrees of freedom and the significance level $\alpha$. If $t_{\mathrm{kj}}>\mathrm{t}_{\mathrm{tabl}}$, then the coefficients of the model will adequately explain the independent variables.

In accordance with our assumption that conclusion of regional trade agreements has a direct impact on migration processes in the countries that are parties to an integration association, we have developed a regression model in which the dependent variable i.e., the increase of the number of migrants (NM) has been put in compliance with these dependent variables: the level of integration (IL), GDP growth rate of an integration association (GDP) and a growth rate of remittances paid by migrants through money transfer (RM).

\section{Results}

Sixteen integration associations have been examined in this study; each of these associations is characterised by different levels of liberalisation of the movement of labour migrants (see Table 1).

The statistical base of the model therefore includes the average growth rates of the variables studied in regression for 2010-2015 for each of the integration associations. The average growth rates $\left(\mathrm{T}_{\mathrm{av}}\right)$ of relevant values have been determined for each country of the corresponding RTA:

$$
\mathrm{T}_{\mathrm{av}}=\sqrt[5]{\frac{Y_{2015}}{Y_{2010}}}
$$

Where $Y_{2010}$ and $Y_{2015}$ are the values of the analysed indicator in 2010 and in 2015 respectively. This approach allows analysing trends in the dynamics, which increases the accuracy of the resulting data. If there were no relevant values for certain countries, the 2015 figure was calculated by extrapolating the data from the entire period of time given in the statistical base (Table 2).

\begin{tabular}{lcccc} 
Table 2: Initial values of regression variables & Average GDP & Average growth \\
RTA & $\begin{array}{c}\text { Average rate of } \\
\text { increase in the } \\
\text { number of } \\
\text { migrants, } \%\end{array}$ & $\begin{array}{c}\text { Level of } \\
\text { integration }\end{array}$ & $\begin{array}{c}\text { Avrowth rate, \% } \\
\text { grow }\end{array}$ & $\begin{array}{c}\text { remittances } \\
\text { received, \% }\end{array}$ \\
\hline EU & 1.5 & 5 & 1.6 & 1.74 \\
ECCAS & 8.94 & 4 & 6.6 & 6.88 \\
EAEU & 6.89 & 4 & 0.9 & 1.2 \\
CARICOM & 9.06 & 4 & 2.1 & 3.37 \\
GCC & 9.95 & 3 & 2.2 & 7.45 \\
ASEAN & 8.5 & 3 & 5.61 & 20.4 \\
MERCOSUR & 7.98 & 3 & 1.5 & 5.59 \\
CAN & 9.47 & 2 & 2.1 & 11.2 \\
ECOWAS & 10.9 & 2 & 7.1 & 19.1 \\
SADC & 14.76 & 2 & 5.2 & -1.08 \\
ANZCERTA & 9.65 & 1 & 5.3 & 5.25 \\
COMESA & 7.05 & 1 & 6.1 & -6.46 \\
NAFTA & 7.45 & 1 & 3.34 & 0.55 \\
CIS & -4.59 & 1 & -8.7 & 0.79 \\
SAARC & 9.77 & 1 & 6.15 & 5.98 \\
IGAD & 6.68 & 0 & 6.5 & 14.1 \\
\hline
\end{tabular}

Source: Calculated by the author based on the data given in (United Nations, 2016; The World Bank, 2018a,b). 
On the basis of the data presented in Table 2 a model factors placement chart has been constructed in order to verify the possibility of their analysis by linear regression methods:

\section{Figure 1: Verification of the model initial data for compliance with the assumption of linear} regression

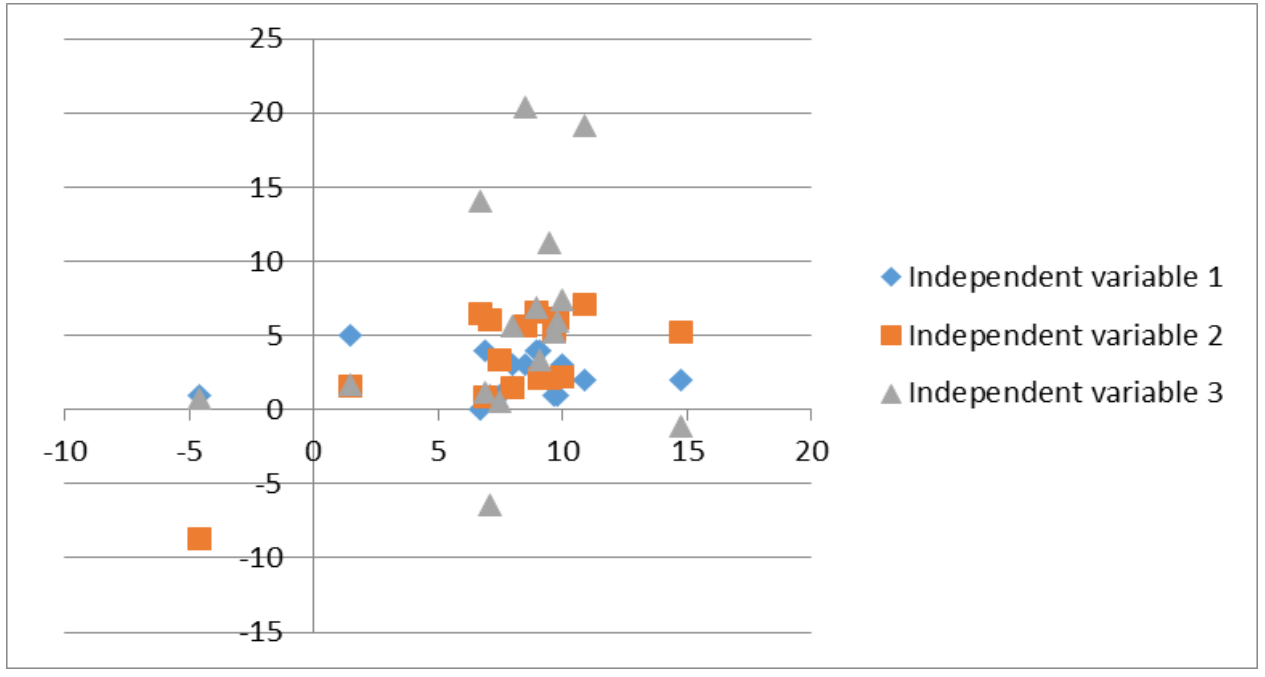

Note: Independent variables of levels 1,2,3 of integration, average GDP growth rate of a RTA, average growth rate of remittances received, respectively.

Fig. 1 shows the value of the dependent variable for each of the factors marked along the abscissa axis, with that of the independent variables, along the ordinate axis. The factor location analysis of the model suggests that most of the values are located around the conditional centre, that is, a linear relationship can exist between the independent and dependent variables. Thus, the linear regression equation will be as follows:

$$
N M=a_{0}+a_{1} L I+a_{2} G D P+a_{3} R M,
$$

where $N M$ is a rate of increase in the number of migrants, $I L$ is a level of integration, $G D P$ is a GDP growth rate of an integration association and $R M$ is a growth rate of remittances paid by emigrants, $a_{0 . .} a_{3}$ are coefficients characterising the degree of influence of each of the independent variables on the rate of increase in the number of migrants.

As a result of the calculations made, the regression equation is as follows:

$$
N M=4,46+0,21 \times L I+0,86 \times G D P-0,02 \times R M
$$

The value of the coefficients in front of each of the factors indicates the degree of influence of one of the independent variables (provided that the rest of variables remain unchanged) on the growth in the number of migrants. The $3^{\text {rd }}$ coefficient is a small negative value, which indicates the existence of a reverse causality between the independent and dependent variables, that is, an increase in the value of the factor by $1 \%$ leads to an insignificant decrease in the number of migrants. This dependence can be explained by the fact that the regions attracting immigrants are primarily the regions of the origin of remittances rather than the regions of their destination, and an influx of additional migrants into the region (which is often ensured by an influx of extraregional labour) does not correlate with the amount of received remittances in the region, since both the correlation value and the determination coefficient for migration and remittances received globally approaches 1 (in fact, the point at issue is the existence of a direct linear dependence between the number of emigrants on a global scale and global volumes of remittances).

Out of the two factors that have a positive influence on the economic growth, a GDP growth rate is the most important one, with its increase by $1 \%$ causing a similar increase in the number of migrants by $0.86 \%$. Particularly noteworthy is that the level of integration within the framework of a particular RTA has a positive impact on an increase in the number of labour migrants, which confirms our hypothesis that a direct correlation between these indicators exists.

The multiple correlation coefficient $\mathrm{R}$ in this model (0.77) characterises as high (according to the Chaddock scale) the qualitative characteristic of the force of interaction. To verify the adequacy of the model, standard tests were used, first of all, the value of the determination coefficient R2 
totalling 0.6 , which, taking into account the number of observations (16), is an indicator of a high reliability of the model; that is, the dispersion of the values of the increases in the number of migrants in general corresponds to real indicators. The P-values for the coefficients were respectively $0.024,0.037,0.017$ and 0.044 , that is, all the determined coefficients are significant and are lesser than the established significance level of 0.05 .

\section{Discussion}

Our study of the key RTAs in the world accounting for more than $90 \%$ of all labour migrants globally, demonstrates a strong correlation between international labour migration and GDP growth in host countries (1\% GDP growth correlates with a $0.86 \%$ increase in migrant inflow). This result should be interpreted bilaterally, insofar as there is interplay of economic growth and an increase in the number of manpower in a host country. The fact of economic growth makes host countries more attractive to migrants; on the other hand, an additional increase in labour provides further support for such growth. At the same time, the regional integration indicator, due to the regulatory factor, is clearly a factor affecting the volume of migration. Thus, having obtained the result of 0.21 , we can insist that there is a positive effect of deepening regional integration on the growth of the volumes of labour migration.

Analysing the received result of the impact of regional integration on migration processes (with the data analysed for the period of 2010-2015), it is especially worth noting that they coincide at their vector with other theoretical and empirical studies of this subject, in particular, with the study by I. Figueiredo, who examined the 1960-2010 period (Figueiredo, Lima \& Schaur, 2014). If that study demonstrated with the help of a gravitational model the positive effect of an RTA on the increase of migration at the level of $27 \%$, our correlation-regression analysis showed $21 \%$, although it addressed the impact of regional integration on the growth of international migration in general, not focusing exclusively on regional gains, having thus expanded the analysis in the new conditions.

\section{Appendix A. Supplementary material}

Supplementary data associated with this article can be found, in the online version, at https://dx.doi.org/10.14254/jems.2018.3-1.7.

\section{Funding}

The authors received no direct funding for this research.

\section{Citation information}

Stakanov, R. (2018). The role of regional migration policy in the development of migration processes. Economics, Management and Sustainability, 3(1), 70-78. doi:10.14254/jems.2018.3-1.7.

\section{References}

Czaika, M., \& Parsons, C. R. (2016). Supply-driven policy systems prove most effective in attracting high-skilled migrants. Retrieved from https://www.knomad.org/sites/default/files/201703/Policy\%20Brief\%205\%20Attracting\%20High-Skilled\%20Migrants.pdf

Department of Economic and Social Affairs United Nations New York. (2015). International Migration Report $2015 \quad$ Highlights. Retrieved from http://www.un.org/en/development/desa/population/migration/publications/migrationre port/docs/MigrationReport2015_Highlights.pdf

European Central Bank. (2004). Regional Economic Integration. Retrieved from https://www.ecb.europa.eu/pub/pdf/other/regionaleconintegrationglobalframework2005e n.pdf?7ac24500beb528b3d89df3374dd5d5df

Figueiredo, E., Lima L. R. \& Schaur G. (2014). Robust estimation of international trade specifications with heterogeneity in distance and policy effects. Retrieved from https://editorialexpress.com/cgi-

bin/conference/download.cgi?db_name=MWITSpring2016\&paper_id=22

OECD. (2014). Labor Migration, Skills \& Student Mobility in Asia. Retrieved from http://www.oecd.org/migration/Labour-migration-skills-student-mobility-in-Asia.pdf 
OECD. (2016). International Migration Outlook 2016. Retrieved from http://dx.doi.org/10.1787/migr_outlook-2016-en

The World Bank. (2018a). Personal remittances, received (current US\$). Retrieved from https://data.worldbank.org/indicator/BX.TRF.PWKR.CD.DT

The World Bank. (2018b). GDP (current US\$). Retrieved from http://data.worldbank.org/indicator/NY.GDP.MKTP.CD

United Nations. (2015). Trends in international migration. Retrieved from http://www.un.org/en/development/desa/population/migration/publications/populationf acts/docs/MigrationPopFacts20154.pdf

United Nations. (2016). Trends in International Migration Stock: The 2015 Revision. Retrieved from http://www.un.org/en/development/desa/population/migration/data/estimates2/docs/M igrationStockDocumentation_2015.pdf

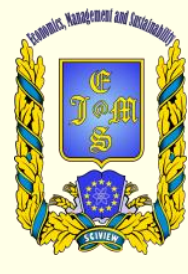

(c) 2016-2018, Economics, Management and Sustainability. All rights reserved.

This open access article is distributed under a Creative Commons Attribution (CC-BY) 4.0 license.

You are free to:

Share - copy and redistribute the material in any medium or format Adapt - remix, transform, and build upon the material for any purpose, even commercially.

The licensor cannot revoke these freedoms as long as you follow the license terms.

Under the following terms:

Attribution - You must give appropriate credit, provide a link to the license, and indicate if changes were made.

You may do so in any reasonable manner, but not in any way that suggests the licensor endorses you or your use.

No additional restrictions

You may not apply legal terms or technological measures that legally restrict others from doing anything the license permits.

Economics, Management and Sustainability (ISSN: 2520-6303) is published by Scientific Publishing House "CSR", Poland, EU and Scientific Publishing House "SciView", Poland

Publishing with JEMS ensures:

- Immediate, universal access to your article on publication

- High visibility and discoverability via the JEMS website

- Rapid publication

- Guaranteed legacy preservation of your article

- Discounts and waivers for authors in developing regions

Submit your manuscript to a JEMS at http://jems.sciview.net or submit.jems@sciview.net 